\title{
The Susceptibility of Doubly Suprarenalectomized Rabbits to Nicotine, Histamine, Ephedrine and Typhoid Vaccine.
}

\author{
$\mathrm{By}$ \\ KOGORO OIKAWA. \\ (及川幸五郎) \\ (From the Physiological Laboratory of Prof. I. Sataki, \\ Tohoku Imperial University, Sendai.)
}

In the same manner as in the acetonitril experiments, ${ }^{1}$ reported in a former paper, nicotine, histamine, ephedrine and typhoid vaccine were applied to the rabbits, long surviving double suprarenalectony, and their resistance to such chemicals was compared with that of normal rabbits, which were poisoned at the same time.

I.

Nicotine.

It is well established that nicotine acts upon the suprarenal medulla itself, whereby epinephrine is liberated into the blood therefrom, ${ }^{2}$ and hyperglycaemia is induced in rabbits by nicotine only by intermediation of the suprarenal bodies. ${ }^{3)}$ These facts led us to inrestigate with much interest the resistance of rabbits without the suprarenals.

Working on rats Crivellarit) reported in 1926 that the lethal dose of nicotine was found to be $17.5 \mathrm{mgrm}$. per kilo for doubly supra-

1) Oika wa, Tohoku J. of Exp. Med., 1931, 18, 1.

2) Sug a war a, Ibid., $1925,6,430$; a rather complete review there.

In order to complete the review the following two reports may be supplemented. Houssay and Molinelli concluded similarly with Sugawara on dogs, the supr:treno-jugular anastomosis method being resorted to (Rev. Soc. Argentina Biol., 1925, 1 year, No. 5 (reprint); C. R. Soc. Biol., 1925, 93, 1124; Am. J. of Physiol., 1926, 76, 551.). According to IIolinelli the epinephrine output in dogs poisoned with diphtheri: toxin was not augmented by nicotine in such a degree as in normal dogs (Rer. SulAmer. de Endocrinologia, Inmunologia y Quimioterapia, 1926, 9 year, 922.).

3) In a b a and O ik a wa, Tohoku J. of Exp. MIed., 1930, 16, 169.

4) Crivellari, Rev. Socied. Argentina de Biol., 1926, 2 sear, $4.51 \mathrm{fr}$. (reprint); (C. R. Soc. Biol., 1927, 96, 223; Am. J. of Physiol., 1927, 81, 414. 
renalectomized rats 18 to 24 days after operation in contrast to 27.5 mgrm. for normal ones, but this increased sensitiveness disappeared 68 days after the operation.

1 per cent solution of nicotine (Merck) in $0.85 \%$ saline solution was prepared, and before use its given amount, according to dosage, was always made up to 5 c.c. by further adding $0.85 \%$ saline solution and injected into the ear vein in a rate of 0.5 c.c. per minute. The rate with which the poison solution is introduced was thus kept uniform, as the intensity of poisoning depends not only upon the absolute amount of the drug introduced, but also upon the amount introduced per unit of time. And for this reason the experiments in which some portion of the total amount of the poison solution, that is 5 c.c., was already sufficient to elicit severe poisoning symptoms so that the total amount seemed to us too excessive to result in the death of the animal and kept from further injection, were arranged under the lot of that concentration of nicotime, but not of the total quantity actually introduced, and their outcome was taken as fatal, though actually they survived.

The experiments with one and the same dose on doubly decapsulated rabbits and control ones as well were always run at the same date.

\section{Results:}

Nicotine was given intravenously to 25 doubly decapsulated rabbits and 33 normal ones, all male. The interval elapsing between the last decapsulation and nicotine poisoning was 68 to 478 days, mean about 220 days, and that between the first operation and nicotine poisoning 82 to 556 days, mean about 280 days.

Dose: $1 \mathrm{mgrm}$. nicotine per kilo body weight and $3 \mathrm{mgr} \mathrm{m}$. $1 \mathrm{mgrm}$. was incapable of causing poisoning symptoms when applied to 3 normal rabbits. One rabbit received $3 \mathrm{mgrm}$. nicotine, which was followed by quick respiration.

Dose: 5 mgrm. This dose was tried on one doubly decapsulated labbit and soon occasioned some symptoms: salivation, restlessness, laboured respiration, a small dilatation of pupil, dyspnoea, lay on its side unconsciously, respiration weak and slow, ear cyanotic, pupil constricted, heart quick, respiration slow but afterwards increased in rhythm. At the end of 3 hours after nicotine injection the behaviour returned to normal.

One normal animal was also poisoned with this dose with nearly the same results as with the doubly decapsulated, only in this animal opistotonic convulsions occurred.

Dose: $6 \mathrm{mgrm}$. Of 3 rabbits without both glands two were capable of surviving, while one (B 55) died. The latter was injected with 
nicotine 344 days after the last decapsulation, and showed typical symptoms but without convulsions, but looked normal at the end of 3 hours after injection. Nevertheless it died later, about 24 hours after injection; the outcome was noted as "survived" in Table I, because of surviving intoxication 24 hours. The other two animals showed also poisoning symptoms as B 55, but they lasted only one hour and they survived. One normal rabbit was given this dose, typical intoxication symptoms soon became manifest but no convulsions. These symptoms disappeared a few minutes later, only respiration and heart beat were a little quick for a while.

Dose: $7 \mathrm{mgrm}$. All five suprarenalectomized rabbits survived this dose. Two rabbits (B 92 and 024 , nicotine 336 or 117 days after the last decapsulation) neither lay down nor lost consciousness, while others (nicotine 79 to 118 days after the last operation) did so, without convulsive attacks.

Two control rabbits survived. They fell flat on their abdomen unconscious, but with convulsive seizures. The normal behaviour was restored 50 minutes after injection.

Dose: 8 mgrm. Of 5 operated animals two survived, three died. The former (B $93 \&$ B 37, nicotine 300 respectively 118 days after the last decapsulation) lay down unconscious but with no convulsions, 15 or 40 minutes later they resumed a normal posture, only respiration and heart beat were still quick. Two rabbits (B $26 \&$ S 6 , nicotine 336 or 366 days after the last operation) died under violent symptoms immediately after injection. The other (B 60, nicotine 117 days after. the last operation) was killed by 3.5 c.c. out of 5 c.c. nicotine solution (actual amount per kilo $5.6 \mathrm{mgrm}$. nicotine), which immediately evoked opistotonic convulsions.

5 normal rabbits survived this dose. Remarkable symptoms were observable, and one rabbit (5) fell over on its side without signs of reflexes some minutes after injection.

Dose : $9 \mathrm{mgrm}$. One doubly suprarenalectomized rabbit lay down unconscious some minutes after injection, but survived. Of 5 control animals 2 survived and 2 died actually. The remaining (5) already indicated serious symptoms when 1.5 c.c. out of 5 c.c. nicotine saline fluid were injected, that is $2.7 \mathrm{mgrm}$. actually introduced, therefore $9 \mathrm{mgrm}$. per kilo was taken as certainly fatal to it. In two fatal cases opistotonic convulsions occurred, while only the other symptoms were noted in the survived instances.

Dose: $10 \mathrm{mgrm}$. Of the operated lot, one survived and 4 died. Rabbit $B 92$ received this dose 343 days after the last decapsulation, fell down immediately without reflexes, but was not attacked by convulsions; respiration and pulse became slow but again quick gradually 5 minutes after 
TABLE I.

Nicotine to the rabbits, long surviving the double suprarenalectomy.

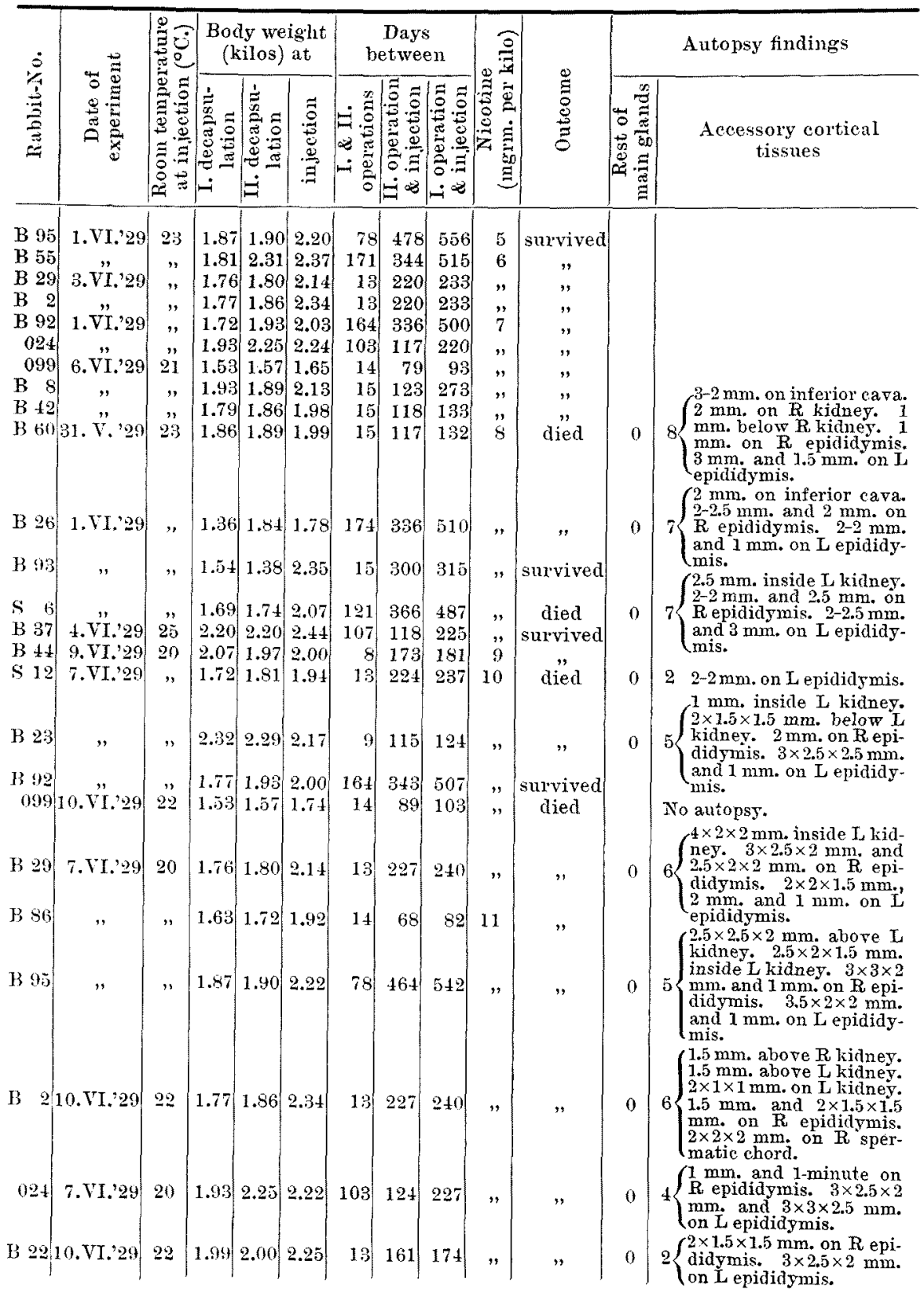


TABLE II.

Nicotine to normal rabbits.

\begin{tabular}{|c|c|c|c|c|c|c|c|c|c|c|c|}
\hline 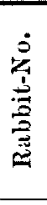 & 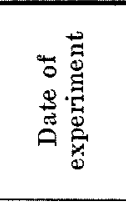 & 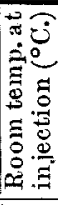 & 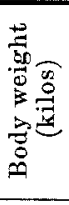 & 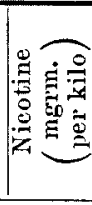 & 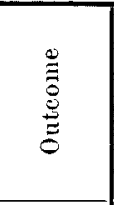 & 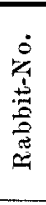 & 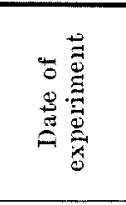 & 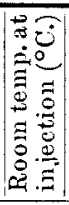 & 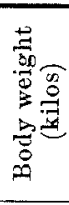 & 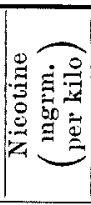 & $\begin{array}{l}\stackrel{\Xi}{\Xi} \\
\stackrel{\Xi}{\Xi} \\
\stackrel{\Xi}{\Xi}\end{array}$ \\
\hline 1 & V. '29 & 18 & 1.72 & 1 & strivived & 5 & 3.VI.'29 & 23 & 1.89 & 9 & died \\
\hline 2 & 30. V.'29 & 21 & 1.71 & $"$ & $"$ & 1 & 31. v. 29 & 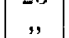 & 1.85 & 10 & $"$ \\
\hline 3 & & $"$ & 1.70 & " & $"$ & 2 & , & $"$ & 1.66 & " & $"$ \\
\hline 1 & 30. V. '. 29 & $"$ & 1.72 & 3 & ," & 3 & ," & ," & 1.8 & $"$ & \\
\hline 1 & - & $"$ & 1.71 & 5 & ", & \pm & $"$ & $"$ & 1.77 & $"$ & survi \\
\hline 1 & $"$ & $"$ & 1. & 6 & $"$ & 5 & & 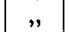 & 1.5 & 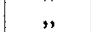 & \\
\hline 1 & " & ", & 2.2 & 7 & ", & 1 & 30. V. 29 & 21 & 2.0 & 11 & died \\
\hline 2 & & $"$ & 1 . & & " & 2 & & & 1. & $"$ & $"$ \\
\hline 1 & 4. VI.'29 & 25 & 1. & 8 & " & 3 & 1.VI.'29 & 23 & 2.1 & $m$ & 3 \\
\hline 2 & $"$ & ", & 1. & " & $"$ & 4 & 4. VI.'29 & 25 & 2. & $"$ & survi \\
\hline 3 & & $"$, & 2. & ", & & 5 & & $\infty$ & 2.17 & & died \\
\hline 4 & " & $"$ & & " & $"$ & 1 & 6. VI.'29 & 21 & 2. & 12 & $n$ \\
\hline 5 & & & 1. & & & 2 & & , & 1. & & \\
\hline te & 30. & 21 & & 9 & & 3 & & & & $"$ & $"$ \\
\hline 2 & & 23 & 2.05 & $"$ & died & 4 & 7.VI.'29 & 20 & 1.8 & & , \\
\hline 3 & $3 . \mathrm{V}$ & , & 1.90 & 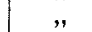 & , & $\tilde{y}$ & 14.VI.'29 & 29 & 1.86 & $"$ & $"$ \\
\hline 4 & & 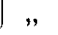 & 2.0 & & survive & & & & & & \\
\hline
\end{tabular}

TABLE III.

Nicotine Summary Talle.

\begin{tabular}{c|c|c|c|c}
\hline \multirow{2}{*}{ Dose per kilo } & \multicolumn{2}{|c|}{$\begin{array}{c}\text { Doubly suprarenalectomized } \\
\text { rabbits }\end{array}$} & \multicolumn{2}{|c}{ Normal rabbits } \\
\cline { 2 - 5 } (mgrm.) & Survived & Died & Survived & Died \\
\hline 1 & & & 3 & \\
3 & & & 1 & \\
5 & 1 & & 1 & \\
6 & 3 & & 1 & \\
7 & 5 & & 5 & 3 \\
8 & 2 & & 2 & 3 \\
9 & 1 & 5 & 2 & 5 \\
10 & 1 & 5 & 1 & 5 \\
11 & & & & 5 \\
12 & & & & \\
\hline
\end{tabular}

injection, and normal posture was regained about a half hour later. Two rabbits ( $099 \&$ B 29) were attacked by convulsions immediately after nicotine poisoning and died soon after. One rabbit (B 23, 115 days after the last operation) was killed by 3 c.c. out of 5 c.c. nicotine saline solution, that is $6 \mathrm{mgrm}$. per kilo, convulsions being noted after a short apnoea. The rest (S 12, 224 days after the last decapsulation) in- 
dicated already severe symptoms when 3 c.c. were injected, so that 5 c.c. were assumed undoubtedly as fatal to this animal.

Of the control series, two survived, one without losing consciousness, the other lost it, and three died. Of the latter one died under convulsions immediately after injection, the second (Rabbit 3) was killed by 3.5 c.c. out of 5 c.c. (actual amount injected: $7 \mathrm{mgrm}$. per kilo), and in the third (No.2) opistotonic convulsions already took place when 2.6 c.c. were injected, so that this case was taken as fatal.

Dose: $11 \mathrm{mgrm}$. All 5 rabbits deprived of the suprarenals showed convulsions which were immediately followed by death. Rabbit B 86 died on application of only 3 c.c. out of 5 c.c., viz. actual amount of $6.6 \mathrm{mgrm}$. nicotine per kilo. Of the control set, one survived, four succumbed. Rabbit No. 4 suffered from nicotine intoxication, but no convulsions occurred, and 40 minutes after injection the animal behaved as normal. Rabbit No. 3 was killed by 3.5 c.c. of 5 c.c. nicotine saline, that is, actual amount of $7.7 \mathrm{mgrm}$. per kilo, and Rabbit No. 1) indicated already serious symptoms even with 1 c.c. out of 5 c.c. nicotine saline fluid (actual amount $2.2 \mathrm{mgrm}$. per kilo), so that it was recorded as a fatal case. The two other rabbits were attacked by convulsions immediately after nicotine poisoning, and died in a short time.

Dose: $12 \mathrm{mgrm}$. All 5 control rabbits died soon after injection. Rabbit No. 1 received only 4 c.c. out of 5 c.c. (actual amount $9.6 \mathrm{mgrm}$. per kilo) and Rabbit No. 5 by 3.5 c.c. (actually $8.4 \mathrm{mgrm}$. per kilo).

As is readily seen from the data above related, summarized in Tables I and $I$, and further briefly epitomized in a small table (Table $\mathrm{II}$ ), the intravenous maximum non-lethal dose of nicotine for normal rabbits was found as $8 \mathrm{mgr} m$. per kilo body weight, and for those rabbits long surviving double suprarenalectomy (mean 220 days after it; only in 3 cases out of 25 nicotine was given earlier than 100 days after the last decapsulation.) $7 \mathrm{mgrm}$. per kilo, and the minimum lethal dose for the former 12 mgrm. per kilo and for the latter $11 \mathrm{mgrm}$.

The actual amount of nicotine injected in the cases where a large amount of nicotine per unit of time was applied and some portion of the total nicotine saline solution, that is 5 c.c., which was to be injected in 10 minutes with velocity as uniform as possible, killed already the animal, be taken into consideration, the whole features of the experimental outcome are not altered.

The M. L. D. of nicotine for rabbits by intravenous application is given as $10 \mathrm{mgrm}$. per kilo in Soll ma n n. ${ }^{5}$ ) Taka ha sh $\left.{ }^{6}{ }^{6}\right)$ found it as $30 \mathrm{mgrm}$. per kilo for adult rabbits and $45 \mathrm{mgrm}$. for young. The latter was determined by estimating quantities sufficient to kill the animals between 50 and 60 minutes when injected into the vein.

5) Sollm an n, A laboratory guide in pharmacology, 1917 Philad. and Lond., 331.

6) Takah a shi, Tohoku J. of Exp. Med., 1925, 6, 72. 
Further when smaller doses than the maximum non-lethal dose were given it was readily observable that the poisoning symptoms were more severe in the animals operated on. In advance it must be added that doubly suprareualectomized animals were in general slow in recovering from the severe poisoning, so that even on the next day after nicotine poisoning such animals often suffered from some aftereffect such as poor appetite.

While the both heart ventricles of normal rabbits, died of nicotine poisoning, were found in the diastolic state at the immediate necropsy, the left ventricle of the doubly suprarenalectomized ones was constricted and the right dilated.

In conclusion the account of the epinephrine content of both glands of the rabbits received $12 \mathrm{mgrm}$. nicotine per kilo, which was determined by $\mathrm{Su}$ to and Koji m a, ${ }^{7}$ may be added. They were $0.12 \mathrm{mgrm} ., 0.024 \mathrm{mgrm}, 0.09 \mathrm{mgrm}$. and $0.034 \mathrm{mgrm}$. The glands taken out immediately after death by nicotine poisoning held a far smaller quantity of epinephrine than normal.

\section{Résumé :}

When rabbits were examined $68-478$ days, mean 220 days (in most. cases over 100 days) after double suprarenalectomy, the sensibility to nicotine was still greater than in normal ones, though only a little. In making this deduction the maximum non-lethal dose and the minimum lethal dose as well as further severity of poisoning symptoms in cases of smaller doses and the after-effect in general were all taken into account. These factors harmonize well with each other.

II.

\section{Histamine.}

That the double ablation of the suprarenals diminishes largely the resistance of animals to histamine is a fact accepted by all the investigators who have attacked this question. Cats, rats and dogs were experimented on. Dale $e^{8)}$ came to see a remarkable lack of resistance to histamine intravenously given in cats deprived of their suprarenals. While $10 \mathrm{mgrm}$. histamine per kilo was tolerated in normal cats with but slight and transitory effects, the resistance of the cats, the suprarenals of which were removed on the previous day, was found to be reduced to a very low level, as little as $0.16 \mathrm{mgrm}$. per kilo.

A similar finding was obtainable in the hands of Kellaw a $y$ and Cowell, ${ }^{9)}$ and they noted that animals in which the cortex of one gland was severely damaged without corresponding injury to the me-

7) K o jim a, Tohoku J. of Exp. Med., 1928, 10, 281.

8) D a le, Brit. J. of Exp. Path., 1920, 1, $110 \mathrm{ff}$.

9) Kell aw ay and Cowell, J. of Physiol., 1923, 57, $95 \mathrm{ff}$. 
dulla almost invariably showed, after the extirpation of the fellow gland, hypersensitiveness to small doses of histamine, and further that the reaction became later less evident though the medulla showed no corresponding increase in function as judged by the reaction of the denervated pupil.

While dogs were still in excellent condition after loss of the suprarenals, as 18 to 74 hours, Ban ting and $\mathrm{G}$ airn $\mathrm{s}^{10)}$ gave them histamine and discovered that the drug is about thirty times more toxic after double suprarenalectomy. Two weeks after double removal in rats Crivellar.i found $40 \mathrm{mgrm}$. per kilo as fatal against $500 \mathrm{mgrm}$. for normal ones. Scott's ${ }^{12}$ findings harmonize with Crivellari's, that is $10 \mathrm{mgrm}$. per $100 \mathrm{grm}$. body weight, given intraperitoneally, was usually proved sufficient to kill doubly suprarenalectomized rats in the 2nd week after operation, while such doses produce only transcient symptoms in operated control rats. Gottesman and Gottesman ${ }^{13)}$ also came to a similar conclusion; further they called attention to the fact that the great diminution in resistance of rats to histamine does not occur until about the 5th day after the double removal.

To the rabbits, deprived of the suprarenals and the normal, each 35 in number, histamine was administered in doses varying from 0.4 to $1.2 \mathrm{mgrm}$. per kilo, each dose to 5 rabbits of each set. Suprarenoprived rabbits were experimented on 80 to 232 days after the last decapsulation and 135 to 310 days after the first. Histamine (Grübler) was dissolved in 2 c.c. of 0.85 per cent saline solution and infused into the left ear vein at a rate of 0.5 c.c. a minute.

The minimum lethal dose of histamine, when introduced intravenously to white male rabbits at a rate of 0.5 c.c. per minute, was found in the case of 70 rabbits as $1.2 \mathrm{mgrm}$. per kilo of body weight, and that formd for 35 normal ones here used as the control was quite the same.

Voegtlin and Deyer ${ }^{14)}$ noted that histamine phosphate killed both normal rabbits injected with $2 \mathrm{mgrm}$. per kilo, and $0.5 \mathrm{mgrm}$. per kilo is given in Sollmann and Hanzlik as fatal to rabbits in an intravenous application. ${ }^{15)}$

\section{Results :}

Dose: 0.4 mgrm. histamine (Merek) per kilo body weight. Each group of 5 rabbits of both sets showed anly slight transitory symptoms.

10) Banting and Gairns, Am. J. of Physiol., 1926, 77, $109 \mathrm{f}$.

11) Crivellari, Rev. Soc. Argentina de Biol,, 1926, 2 year, 454 ff, C. R. Soc. Biol., 1927, 96, 223; Am. J. of Physiol., 1927, 81, $416 \mathrm{ff}$.

12) Scott, J. of Exp. Hed., 1928, 47, 185.

13) Gottesm an and Gottes man, J. of Exp. Med., 1928, 47, 503.

14) Voegtlin and Deyer, J. Pharm. and Exp. Ther., 1925, 24, 102.

15) Sollmann and $\mathrm{Hanzlik}$, An introduction to experimental pharmacology, 1928 Philad. and Lond., 284. 
Conjunctiva anaemia, pupil contricted slightly, respiration and heart beat somewhat quick.

Dose : 0.5 ngrm. Of 5 doubly suprarenoprived rabbits 2 (B 84 \& $B$ 10) showed severe symptoms but without any convulsions, but the ather three animals behaved as the 5 normal controls, which indicated slight symptoms.

Dose: 0.6 mgrm. $0.6 \mathrm{mgrm}$. was given to decapsulated rabbits only; of 5 individuals two (B 51 \& No. 66) showed slight symptoms while the others were attacked by severe symptoms but without convulsions.

Dose: $0.7 \mathrm{mgrm}$. All control animals showed symptoms, as myosis and anaemia of conjunctiva, etc., of moderate strength. Of the doubly decapsulated only one rabbit (B 55) showed severe symptoms, myosis and anaemia of high degree and quick breathing and pulse; in the other cases the poisoning was just the same as in the controls.

Dose : $0.8 \mathrm{mgrm}$. Of 5 controls, two (Nos. $4 \& 5$ ) showed violent symptoms, myosis and anaemia of high degree and slow and dyspnoic breathing, and the others moderate grade of poisoning. Of 5 decapsulated rabbits, 3 survived and 2 died. Rabbit (B 44, 106 days after the last decapsulation) died soon after the injection; Rabbit (S. 10, 92 days after the last operation) lay down on its side unconscious immediately after administration of 1.4 c.c. out of 2 c.c. histamine saline solution, that is an actual amount of $0.56 \mathrm{mgrm}$. histamine per kilo, and 15 minutes later the animal regained its normal posture; this was assumed as a fatal case. Rabbit $(044,94$ days after the second decapsulation) showed very serious symptoms, anaemia of mucosae and myosis of the maximum grade, slow breathing, heart beat accentuated, irregular, the animal lay down on its side unconscious; some minutes later respiration gradually became quick and heart beat regular and quick, and a few minutes later the normal posture was regained. The other 2 rabbits survived with somewhat remarkable symptoms.

Dose : $0.9 \mathrm{mgrm}$. All 5 controls survived this dose; violent symptoms, the maximum constriction of pupils and the highest degree of anaemia of mucosae, lacrimation, slow and dyspnoic breathing, slow, arrhythmic and accentuated heart beat, were observed in two rabbits (Nos. 3\& 4), but in the others poisoning was not so serious. Of 5 decapsulated ones, 2 survived and 3 died. Two rabbits, (B $83 \&$ No. 7 both 84 days after the last operation) indicated violent symptoms, lay flat on the abdomen unconscious with dyspnoic respiration and irregular heart beat, but survived. Rabbit (B 92, 121 days after the last operation) fell over on its side unconscious when 1.5 c.c. out of 2 c.c. histamine saline solution was infused, opistotonus followed. 10 minutes later the animal appeared nearly normal; but this was taken as fatal 
TABLE IV.

Histamine to the rabbits, long surviving the double suprarenalectomy.

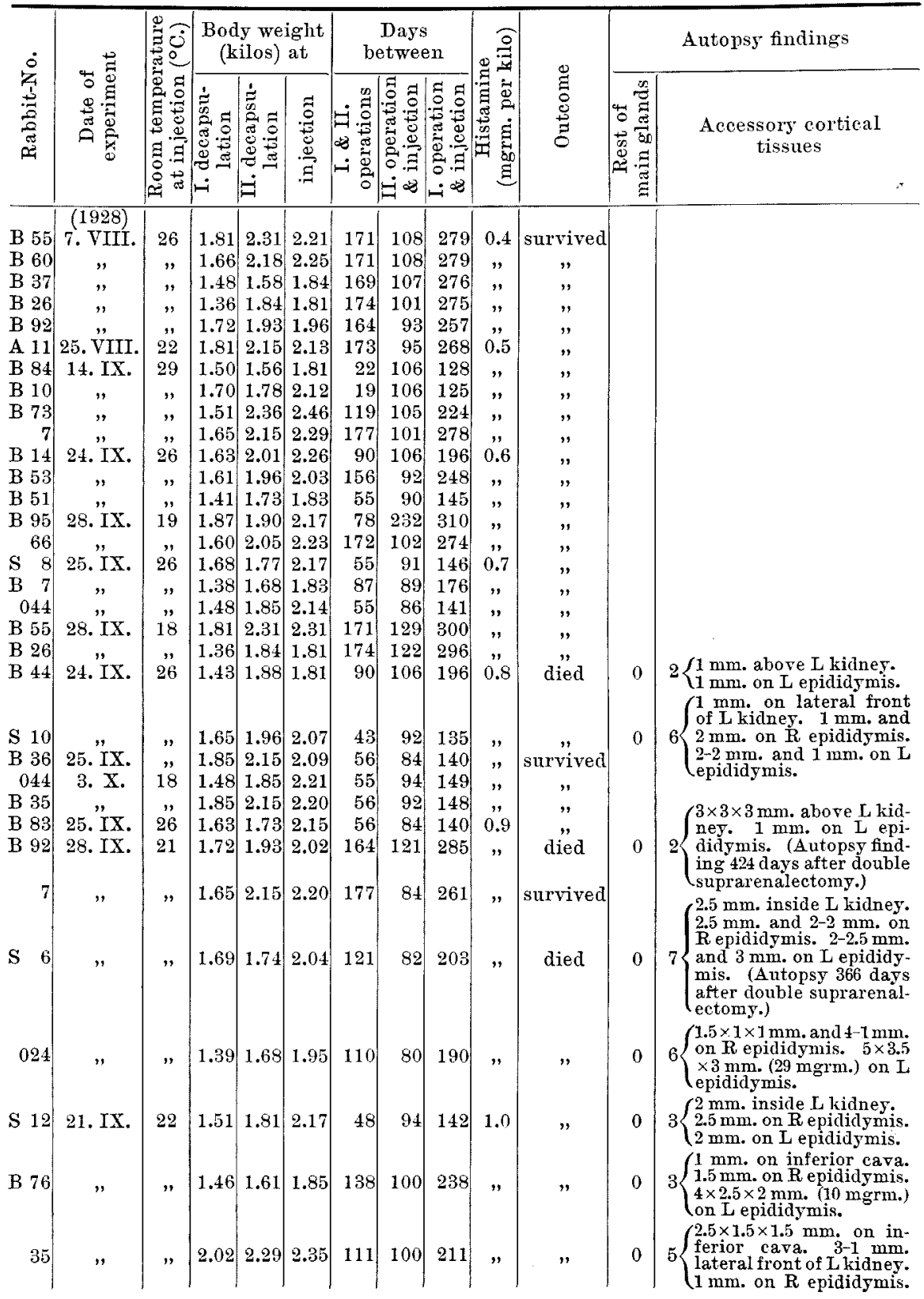




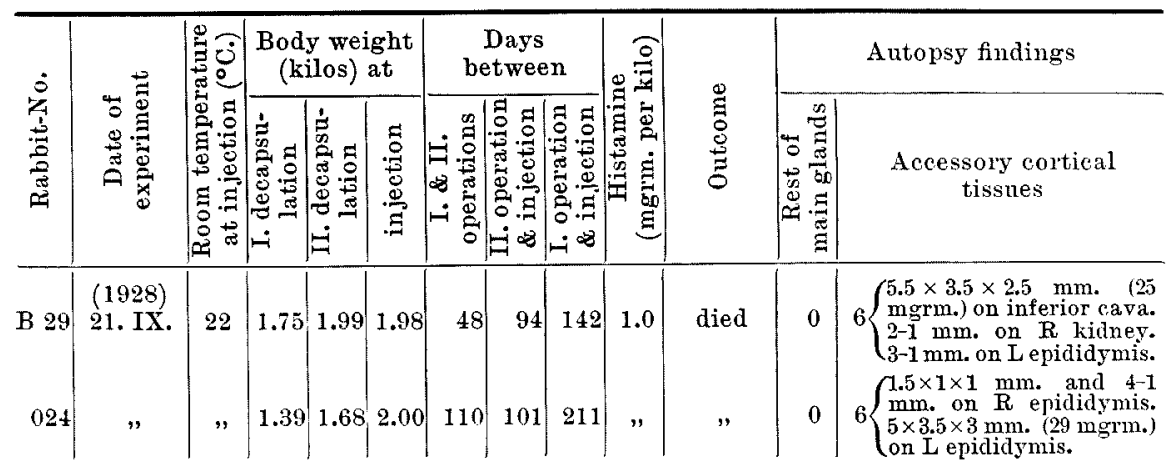

on comparing the severity of the symptoms and the actual amount given. One rabbit (S 6, 82 days after the second suprarenalectomy) was recorded as fatal as serious symptoms occurred already when 1.4 c.c. out of 2 c.c. solution (actual amount of histamine $0.63 \mathrm{mgrm}$. per kilo) was infused. It took 15 minutes before the animal looked normal again. The rest $(024)$ died under convulsions occurring immediately after injecting with 1.8 c.c. in 2 c.c. of histamine saline fluid.

Dose : $1.0 \mathrm{mgrm}$. Of 5 controls 3 survived this dose with remarkable symptoms, but without unconsciousness or convulsions. Two rabbits were killed with 1.3 c.c. respectively 0.8 c.c. out of 2 c.c. histamine saline solution (actual amount infused $0.65 \mathrm{mgrm}$. respectively 0.4 mgrm. per kilo).

5 decapsulated animals showed severe symptoms immediately when administered with 0.5 c.c. out of 2 c.c. of histamine saline solution (Rabbit 0 24, 101 days after the last operation; actual amount of histamine: $0.25 \mathrm{mgrm}$. per kilo), 1 c.c. (Rabbit B 76,100 days after the last decapsulation; actual amount of histamine: $0.5 \mathrm{mgrm}$. per kilo), 0.85 c.c. (Rabbit No. 35, 100 days and 0.425 mgrm. per kilo), 1.3 c.c. (Rabbit B 29, 94 days and 0.65 mgrm. per kilo) and 0.6 c.c. (Rabbit S 12, 94 days and $0.3 \mathrm{mgrm}$. per kilo). They lay down unconscious, but were not attacked by convulsive seizures. From 5 to 10 minutes later normal posture was resumed. These animals were recorded as fatal cases.

Dose : $1.2 \mathrm{mgrm}$. This dose was given only to 5 normal rabbits. One (No. 4 ) died actually on receiving 0.4 c.c. out of 2 c.c. of histamine saline solution. The others were taken as fatal instances, because they showed violent symptoms and only survived their critical canditions with difficulty, even when 0.6 c.c. (No. 1), 0.5 c.c. (No. 2) 0.7 c.c. (No. 3) and 1 c.c. (No. 5) were infused. In Rabbit No. 1 the symptoms were only mild. The actual amounts correspond to $0.36 \mathrm{mgrm}$. per kilo, $0.3 \mathrm{mgrm}$., $0.42 \mathrm{mgrm}$. and $0.6 \mathrm{mgrm}$. 
TABLE V.

Histamine to normal rabbits.

\begin{tabular}{|c|c|c|c|c|c|c|c|c|c|c|c|}
\hline 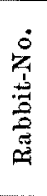 & 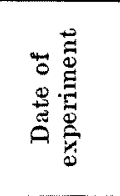 & 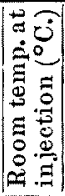 & 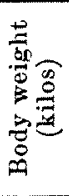 & 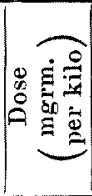 & 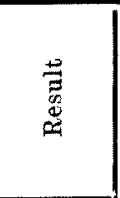 & $\begin{array}{l}0 \\
7 \\
3 \\
0 \\
0 \\
0 \\
0 \\
0 \\
0\end{array}$ & 苍鸪 & 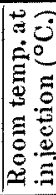 & 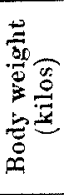 & 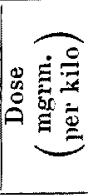 & 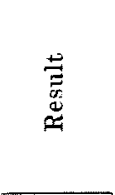 \\
\hline & $(1928)$ & & & & & & $(1928)$ & & & & sulvived \\
\hline 1 & 7. IX. & 26 & 1.90 & 0.4 & survived & 4 & 3. X. & 18 & 1.75 & 0.8 & survived \\
\hline 2 & ", & $"$ & 1.63 & $"$ & " & 5 & ", & , & 1.91 & $"$ & $"$ \\
\hline 3 & " & ", & 1.64 & $"$ & " & 1 & 28. IX. & 21 & 2.13 & 0.9 & $"$ \\
\hline 4 & ," & " & 1.74 & " & " & 2 & ", & $"$ & 1.92 & " & $"$ \\
\hline 5 & $"$ & ", & 1.68 & " & , & 3 & " & $"$ & 1.90 & , & , \\
\hline 1 & 14. IX. & 29 & 1.71 & 0.5 & $"$ & 4 & " & $"$ & 1.80 & " & $"$ \\
\hline 2 & ," & ", & 1.79 & " & $"$ & 5 & $"$ & ," & 1.71 & , & , \\
\hline 3 & $"$ & " & 1.71 & $"$ & " & 1 & $21, \mathbf{I X}$ & 22 & 1.73 & 1.0 & " \\
\hline 4 & $"$ & , & 1.61 & ", & $"$ & 2 & " & ", & 1.74 & , & te \\
\hline 5 & 25. VIII. & 22 & 1.83 & $"$ & ", & 3 & "1 & $"$ & 1.79 & " & died \\
\hline 1 & 25. IX. & 26 & 1.75 & 0.7 & $"$ & 4 & $"$ & $"$ & 1.84 & ", & survived \\
\hline 2 & 28. IX. & 19 & 1.74 & " & ," & 5 & , & $"$ & 1.90 & $"$ & died \\
\hline 3 & , & ", & 2.26 & $"$ & $"$ & 1 & 22. IX. & 23 & 2.09 & 1.2 & ," \\
\hline 4 & ", & $n$ & 1.85 & , & , & 2 & " & $"$ & 1.68 & " & $"$ \\
\hline 5 & , & ," & 1.74 & , & , & 3 & " & $"$ & 1.96 & , & , \\
\hline 1 & 3. $\mathrm{x}$. & 18 & 1.78 & 0.8 & ", & 4 & , & ," & 1.59 & $"$ & " \\
\hline 2 & , & " & 1.68 & ," & ", & 5 & , & ," & 1.82 & $n$ & $"$ \\
\hline 3 & $n$ & " & 1.82 & ", & " & & & & & & \\
\hline
\end{tabular}

TABle VI.

Histamine Summary Table.

\begin{tabular}{|c|c|c|c|c|}
\hline \multirow{2}{*}{$\begin{array}{c}\text { Dose per kilo } \\
\text { (mgrm.) }\end{array}$} & \multicolumn{2}{|c|}{$\begin{array}{c}\text { Double suprarenalectomized } \\
\text { rabbits }\end{array}$} & \multicolumn{2}{|c|}{ Normal rabbits } \\
\hline & Survived & Died & Survived & Died \\
\hline $\begin{array}{l}0.4 \\
0.5 \\
0.6 \\
0.7 \\
0.5 \\
0.9 \\
1.0 \\
1.2\end{array}$ & $\begin{array}{l}5 \\
5 \\
5 \\
5 \\
; \\
2 \\
2\end{array}$ & $\begin{array}{l}2 \\
3 \\
5\end{array}$ & $\begin{array}{l}5 \\
5 \\
5 \\
5 \\
5 \\
5 \\
3\end{array}$ & $\begin{array}{l}2 \\
5\end{array}$ \\
\hline
\end{tabular}

Two protocols are reproduced in order to illustrate the general routine: (21. IX. 1928).

(Control) White male rabbit (No. 3), 1.79 kilos. $1.79 \mathrm{mgrm}$. histamine (Dose $1.0 \mathrm{mgrm}$. per kilo) in 2 c.c. $0.85 \%$ saline solution.

$0: 40$ p.m. Injection. When 1.3 c.c. infused poisoning symptoms occurred. Pupil constricted ad maximum, mucosae (conjunctiva, lips) anaemic, restlessness, now and then convulsive jumps, fell over on its side, respiration slow, deep, dyspnoic, heart beat slow, irregular, highly accentuated, pulse frequency de- 
creased when pupils dilated, and it increased when pupils dilated, these occurred alternately for a while, then respiration and heart beat quicker, salivation increased ; 5 minutes after administration the animal took up apparently a normal position; a few minutes later an attempt was made to fasten it, but this effected pupil constriction and opistotonic convulsions which were followed by death.

(Suprarenalectomized rabbit) White male rabbit (B 29), 1.98 kilos. ( $\mathrm{R}$ suprarenalectomy : 4. V. 1928. 1.75 kilos; L suprarenalectomy : 20. VI. 1.99 kilos). $1.98 \mathrm{mgrm}$. histamine (1.0 mgrm. per kilo) in 2 c.c. $0.85 \%$ saline fluid.

$2: 50$ p.m. Injection; when 1.3 c.c. was infused poisoning symptoms already became manifest, so the injection was discontinued. Pupils constricted ad maximum, mucosae considerably anaemic, restlessness, dyspnoic, then comatose, heart beat slow and irregular but gradually again quick and regular, respiration quick. 10 minutes after the injection the animal in a normal posture, but breathing and heart still quick.

Finally the epinephrine content of the suprarenals of two rabbits dying soon after poisoning will be given here: One rabbit ( 2.1 kilos) received histamine in a dose of $2 \mathrm{mgrms}$. per kilo, the glands immediately taken out weighed R $0.15 \mathrm{grm}$., L $0.169 \mathrm{grm}$., and epinephrine content was estimated by means of $\mathrm{Su}$ to and Kojima's method as $0.272 \mathrm{mgrm}$. per grm. gland. Of another rabbit weighing 1.82 kilos the following figures were noted. $1.2 \mathrm{mgrm}$. histamine per kilo, R gland $0.12 \mathrm{grm}$., L $0.159 \mathrm{grm}$, and epinephrine $0.164 \mathrm{mgrm}$. per grm. gland. It is thus proved that the epinephrine content is reduced in poisoning the rabbit with histamine.

\section{Résumé:}

The minimum lethal dose as well as the maximum non-lethal dose of histamine was thus definitely proved small, but only a little, in the rabbits surviving 80 to 232 days, mean 102 days the double suprarenal ablation, compared with normal ones. The figures were respectively $1.0 \mathrm{mgrm}$. per kilo and $0.7 \mathrm{mgrm}$. per kilo for those operated on against $1.2 \mathrm{mgrm}$. per kilo and $0.9 \mathrm{mgrm}$. for the normal. The severity of poisoning symptoms observable, when smaller doses than the maximum non-lethal were applied, correspond to the above conclusions.

Increase of susceptibility to histamine of other kinds of animals, cats, dogs and rats, shortly or ad maximum 2 weeks after the double loss of glands, reported by the previous experimentalists was of incomparably larger degree.

\section{III.}

\section{EPHEDRINE.}

Ephedrine is an alcaloide which was isolated from the ephedra vulgaris first by $\mathrm{N}$ a gai, about forty years ago and its synthesis and derivatives extensively studied; it is regrettable that this admirable work was published only in Japanese by Dr. N. Nagai although he was a 
master of German. Since the publication of Chen in 1925, who succeeded in isolating it independently of Nagai, it has been studied by a great number of investigators and has vast fields of therapeutic use.

It was attempted to infuse ephedrin "Nagai" of Sankyo Co. in varying doses always dissolved in 2 c.c. of $0.85 \%$ saline solution at a rate of 1 c.c. per 2 minutes in the ear vein of male white rabbits, normal as well as doubly suprarenalectomized; the latter were experimented on over about two months after the last decapsulation.

\section{Results :}

With a dose of 0.001 grm. ephedrine per kilo normal rabbits showed no poisoning symptoms, with $0.005 \mathrm{grm}$. symptoms became manifest, but only transitorily, but with $0.01 \mathrm{grm}$. they became a little remarkable and lasted longer. For example with 0.005 grm. the pupils dilated a little, which lasted about thirty minutes, with 0.01 grm. a moderate dilation of pupils lasted for one hour and with $0.06 \mathrm{grm}$. the maximum dilation occurred as a rule and continued for 5 hours or longer and was accompanied by lacrimation. With a dose of $0.05 \mathrm{grm}$. per kilo or over restlessness and tremor of the musculature set in.

Dose : 0.05 grm. ephedrine "Nagai" per kilo. 5 normal animals indicated a moderate mydriasis and rapid respiration. 5 suprarenalectomized rabbits showed more remarkable symptoms, but survived well.

Dose : $0.06 \mathrm{grm} .5$ suprarenoprived animals were poisoned with this dose. The poisoning symptoms were unmistakably more severe than with $0.05 \mathrm{mgrm}$. The maximum mydriasis, more rapid respiration and tremor of musculature; but they all survived well.

Dose: $0.07 \mathrm{grm}$. 5 control animals showed remarkable poisoning symptoms; the maximum dilation of pupils, lacrimination, faster respiration and heart beat, spasmodic movements of the body; they survived. Of 5 decapsulated rabbits three survived in spite of remarkable poisoning symptoms, and two died. In Rabbit B 73 (106 days after the last decapsulation) epileptic like convulsions with other symptoms occurred a minute after the administration and 3 minutes later the second convulsion attack took place and was followed by stoppage of respiration, but the heart continued to beat ten minutes; Rabbit $B$ 42 (92 days after the last decapsulation) died with convulsions one minute after the injection.

Dose : 0.08 grm. Of 5 normal rabbits 4 especially Rabbit (No. 3) showed violent symptoms. The pupils dilated ad maximum, the animal walked in a spastic like manner, but fell flat on its abdomen, parese of both extremities soon followed, then the breathing became slow and 


\section{TABLE VII.}

Ephedrine to the rabbits, long surviving the double suprarenalectomy.

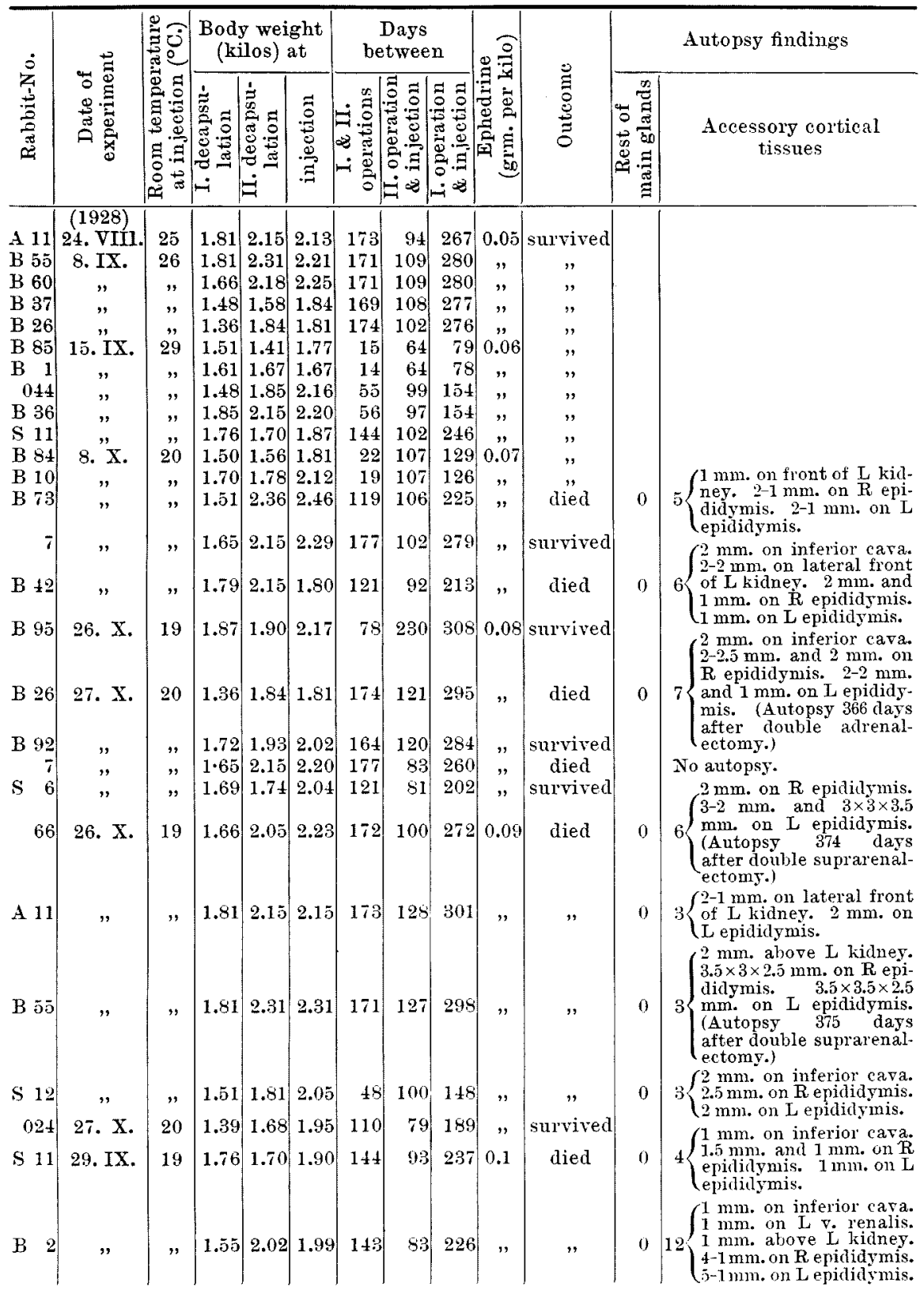




\begin{tabular}{|c|c|c|c|c|c|c|c|c|c|c|c|c|}
\hline \multirow{2}{*}{ 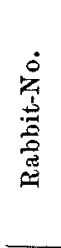 } & \multirow[b]{2}{*}{ 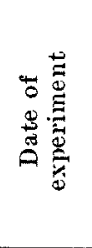 } & \multirow{2}{*}{ 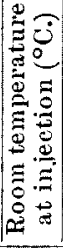 } & \multicolumn{3}{|c|}{$\begin{array}{l}\text { Body weight } \\
\text { (kilos) at }\end{array}$} & \multicolumn{3}{|c|}{$\begin{array}{c}\text { Days } \\
\text { between }\end{array}$} & \multirow{2}{*}{ 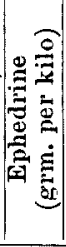 } & \multirow[b]{2}{*}{ 总 } & \multicolumn{2}{|r|}{ Autopsy findings } \\
\hline & & & 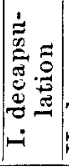 & 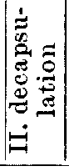 & 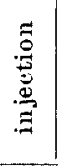 & 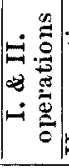 & 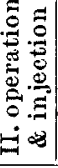 & 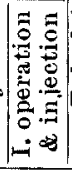 & & & 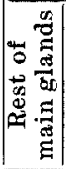 & $\begin{array}{r}\text { Accesso } \\
\text { ti }\end{array}$ \\
\hline 13 & $\begin{array}{l}(1928) \\
\text { 29. IX. }\end{array}$ & 19 & 1.81 & 2.18 & 2.40 & 141 & 83 & 224 & 0.1 & died & 0 & $7\left\{\begin{array}{l}1.5 \mathrm{~mm} . \text { on } \mathrm{L} \\
1.5 \mathrm{~mm} . \text { on R } \mathrm{ep} \\
3-1.5 \mathrm{~mm} . \text { and } 2 \\
\mathrm{~L} \text { epididymis. }\end{array}\right.$ \\
\hline 35 & $"$ & $"$ & 1.96 & 9.01 & 2.13 & 149 & 80 & 229 & $"$ & $"$ & 0 & 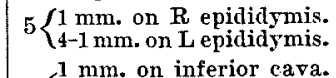 \\
\hline 79 & $"$ & $"$ & 1.99 & 2.16 & 2.34 & 133 & 80 & 213 & ", & " & 0 & $12\left\{\begin{array}{l}1 \text { mm. on } R \text { kidney. } \\
2-1 \mathrm{~mm} \text {. above } \mathrm{L} \text { kidney. } \\
1 \mathrm{~mm} \text {. on } \mathrm{L} \text { kidney. } 2-1 \\
\mathrm{~mm} \text {. on } \mathrm{R} \text { epididymis. } \\
5-1 \mathrm{~mm} \text {. on } \mathrm{L} \text { epididymis. }\end{array}\right.$ \\
\hline
\end{tabular}

dyspnoic; the heart beat quick and strong. 15 minutes later the animal resumed its normal posture. In one rabbit (Rabbit No. 1) the symptoms were never serious. Of 5 decapsulated animals 3 survived despite severe symptoms; the rest were taken as fatal cases as they (Rabbit B 26, 121 days after the last decapsulation and Rabbit No. 7 , 83 days) showed already serious symptoms with convulsions when 1.3 c.c. or 1.5 c.c. out of 2 c.c. ephedrine saline solution was infused.

Dose : $0.09 \mathrm{grm}$. Of 5 control rabbits, 4 survived this dose with violent symptoms except one case (No. 4) which shawed relatively mild symptoms only. One rabbit (No. 5) died under convulsion seizures soon after the intravenous injection. Of 5 suprarenalectomized rabbits one (Rabbit 0 24, 79 days after the last decapsulation) showed serious symptoms but without convulsions, and survived. Two rabbits (S 12 \& A 11, bath 100 days after the last operation) died with convulsions, and the rest ( $66 \&$ B 55,100 respectively 127 days after the second operation) were taken as fatal as serious symptoms with convulsions occurred already when 1.5 c.c. out of 2 c.c. ephedrine saline solution were introduced.

Dose : $0.1 \mathrm{grm}$. Of 5 control animals 3 survived without convulsions. Rabbit (No. 2) died when 1.5 c.c. out of 2 c.c. ephedrine saline solution was injected. The rest died with convulsive attacks immediately after 2 c.c. fluid. Of 5 decapsulated animals one (Rabbit B 2, 83 days after the second decapsulation) died actually with 1.4 c.c. of ephedrine solution, 4 others $(93,83,80$ and 80 days after the second suprarenalectomy) were recorded as fatal because serious symptoms with convulsions already occurred when 1.0, 1.5, 1.4 and 1 c.c. out of 2 c.c. ephedrine saline fluid were given respectively. 
Table VIII.

Ephedrine to normal rabbits.

\begin{tabular}{|c|c|c|c|c|c|c|c|c|c|c|c|}
\hline 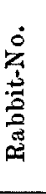 & 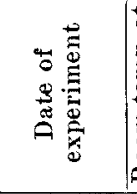 & 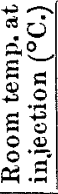 & 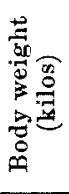 & 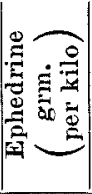 & $\begin{array}{l}\stackrel{g}{\Xi} \\
\stackrel{\Xi}{\Xi} \\
\Xi\end{array}$ & 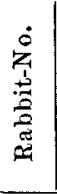 & 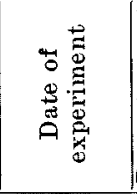 & 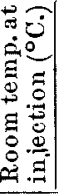 & 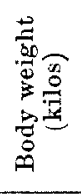 & 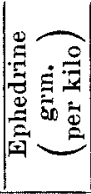 & 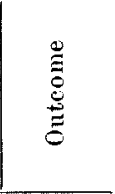 \\
\hline 1 & 8. IX. '28 & 26 & 1.90 & 0.05 & survived & 1 & 26. IX.'28 & 19 & 1.77 & 0.09 & survived \\
\hline 2 & , & " & 1.63 & $"$ & , & 2 &, & $"$ & 2.00 & $"$ & $"$ \\
\hline 3 & $"$ & $"$ & 1.64 & $"$ & $"$ & 3 & ", & 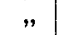 & 1.80 & ", & $"$ \\
\hline 4 & " & " & 1.74 & " & , & 4 & & $"$ & 1.97 & " & \\
\hline 5 & & & 1.68 & & , & 5 & 1. X.'28 & 15 & 2.04 & $"$ & died \\
\hline 1 & 15. IX. '28 & 29 & 1.71 & 0.07 & ", & 1 & 29. IX.' 28 & 20 & 2.17 & 0.1 & survived \\
\hline 2 & ” & $"$ & 1.79 & , & ", & 2 & " & $"$ & 2.01 & ", & died \\
\hline 3 & " & $"$ & 1.71 & , & ", & 3 & $"$ & $"$ & 1.99 & ", & survived \\
\hline 4 & , & ", & 1.61 & 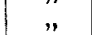 & ", & 4 & ", & 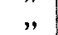 & 1.78 & $"$ & 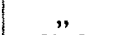 \\
\hline 5 & & & 1.86 & & $"$ & 5 & & 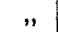 & 1.78 & & died \\
\hline 1 & 1. X.'29 & 15 & 2.05 & 0.08 & $"$ & 1 & 1. X. '28 & 18 & 1.70 & 0.12 & ", \\
\hline 2 & ," & " & 1.85 & $"$ & ," & 2 & ", & $"$ & 1.72 & ", & " \\
\hline 3 & 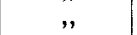 & $"$ & 2.09 & 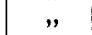 & 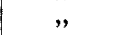 & 3 & " & " & 1.91 & $"$ & $"$ \\
\hline 4 & & $"$ & 1.80 & " & " & 4 & , & $n$ & 1.79 & " & $"$ \\
\hline 5 & 26. IX.'29] & 19 & 1.95 & 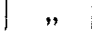 & , & 5 & , & $"$ & 1.72 & $n$ & $"$ \\
\hline
\end{tabular}

TABle IX.

Ephedrine Summary Table.

\begin{tabular}{c|c|c|c|c}
\hline \multirow{2}{*}{ Dose per kilo } & \multicolumn{2}{|c|}{$\begin{array}{c}\text { Double suprarenalectomized } \\
\text { rabbits }\end{array}$} & \multicolumn{2}{c}{ Normal rabbits } \\
\cline { 2 - 5 }$($ grm.) & Survived & Died & Survived & Died \\
\hline 0.05 & 5 & & 5 & \\
0.06 & 5 & 2 & 5 & \\
0.07 & 3 & 2 & 5 & \\
0.05 & 3 & 4 & 4 & 1 \\
0.09 & 1 & 5 & 3 & 2 \\
0.1 & & & & 5 \\
0.12 & & & &
\end{tabular}

Dose : $0.12 \mathrm{grm} .4$ normal rabbits died soon after giving 2 c.c., and one normal one was killed by 1.1 c.c. out of 2 c.c.

The results are given in Tables VII-IX, and two protocols (29. IX. 1928 , room temperature $20^{\circ} \mathrm{C}$.) follow.

(Control) Rabbit No. 3, 2.09 kilos, $0.167 \mathrm{grm}$. ephedrine (0.08 grm. per kilo) in 2 c.c. $0.85 \%$ saline solution.

1:55 p.m. Injection, soon restlessness, muscle tremors, very slow respiration, heart beat quick, accentuated, maximum mydriasis, lacrimation, spastic movements, both extremities paretic, animal lay down on its side, but 15 minu- 
tes after the injection respiration and heart beat quick and the animal regained its normal posture.

(Suprarenalectomized rabbit) Rabbit No. 7, 2.20 kilos. ( $\mathrm{R}$ suprarenalectomy 12. XII. 1927, 1.65 kilos; L suprarenalectomy 6. VI. 1928, 2.15 kilos), $0.176 \mathrm{grm}$. ephedrine (0.08 grm. per kilo) in 2 c.c. saline fluid.

When 1.5 c.c. out of 2 c.c. was given, symptoms occurred, so that no further infusion was carried out. Restlessness, heart beat and respiration quick, pupils dilated ad maximum, spastic movements, suddenly animal lay down on its side unconscious, respiration slow, then epileptic convulsions occurred; then respiration and heart beat became quick and the animal returned to the normal posture.

From the data above given and in the Tables it is without doubt that the rabbits, surviving 64 to 230 days, mean 87 days after the last decapsulation and 78 to 301 days, mean 190 days after the first, were definitely sensitive to ephedrine, though a little, in comparison with the normal. The intravenous maximum non-fatal dose was found 0.06 grm. per kilo and the intravenous minimum lethal dose $0.1 \mathrm{grm}$. for the former in contrast to $0.08 \mathrm{grm}$. and $0.12 \mathrm{grm}$. for the latter.

The intravenous minimum lethal dose of this alcaloid to rabbits is recorded by the previous writers as 60 to 70 mgrms. per kilo ${ }^{16)}$ or 50 mgrms. ${ }^{17}$ ) Lately Suzuki found $0.1 \mathrm{grm}$. per kilo as fatal to rabbits, but not $0.07 \mathrm{grm} .{ }^{18}$ )

Of the suprarenal glands excised immediately after death from ephedrine poisoning the epinephrine content was estimated by means of $\mathrm{K}$ oj i m a's colorimeter and found as largely reduced.

Rabbit 2.01 kilos, $0.1 \mathrm{grm}$. ephedrine per kilo, died with convulsions soon after injection. $\mathrm{R}$ gland $0.3 \mathrm{grm}$., $\mathrm{L}$ gland 0.39 ; epinephrine content of both $0.14 \mathrm{mgrm}$. per grm. Rabbit $1.78 \mathrm{kilos}, 0.1 \mathrm{grm}$. ephedrine per kilo, died after showing serious symptoms. R gland 0.095 grm., L 0.101 grm.; epinephrine content $0.033 \mathrm{mgrm}$. per grm. Rabbit 1.70 kilos, $0.12 \mathrm{grm}$. ephedrine per kilo, died on convulsions soon after injection. $\mathrm{R} 0.188 \mathrm{grm}$., L $0.211 \mathrm{grm}$, epinephrine content $0.112 \mathrm{mgrm}$. per grm. Rabbit $1.72 \mathrm{kilos}, 0.12 \mathrm{grm}$. ephedrine per kilo, died on convulsions soon after injection. R $0.221 \mathrm{grm}$, L $0.365 \mathrm{grm}$.; epinephrine content $0.18 \mathrm{mgrm}$. per grm. Rabbit 1.79 kilos, $0.12 \mathrm{grm}$. ephedrine per kilo, died on severe symptoms. R $0.078 \mathrm{grm}$., L $0.091 \mathrm{grm}$.; epinephrine content $0.069 \mathrm{mgrm}$. per grm. Rabbit 1.72 kilos, 0.12 grm. ephedrine per kilo, died on severe symptoms. R 0.120 grm., L 0.129 grm.; epinephrine content $0.075 \mathrm{mgrm}$. per grm.

\section{Résumé :}

The maximum non-lethal dose as well as the minimum lethal dose of ephedrine, intravenously applied, were proved a little but definitely smaller in the rabbits, which survived well double suprarenalectomy 64 to 230 days, mean 87 days, than in normal rabbits. The figures

16) Che n, J. of Pharm. and Exp. Ther., 1926, 27, 64.

17) Nagel, Arch. f. exp. Path. u. Pharm., 1925, 110, 140 f.; Kreit mair, Ibid., $1927,120,919$.

18) Suz uki, Tohoku J. Exp. Med., 1928, 12, 93. 
were $0.06 \mathrm{grm}$. per kilo and $0.1 \mathrm{grm}$. for the former against $0.08 \mathrm{grm}$. and $0.12 \mathrm{grm}$. for the latter. Severeness of symptoms visible when a much smaller amount of the chemical corresponds to the above difference.

\section{IV. \\ Typhold Vaccine.}

In 1923 and the following year Jaffe and Marine ${ }^{19)}$ reported a marked diminution in the resistance of recently suprarenalectomized rats to typhoid vaccine. They succumbed to one-twentieth of the dose of typhoid vaccine which normal rats readily withstood. They noted further a rapid recovery of the resistance as time elapsed after double decapsulation, as they came to see an increase of the lethal dose as time elapsed and finally to observe about 9 weeks after decapsulation that some rats might show about the same resistance as normal ones.

In the hands of Shiozawa, ${ }^{20>}$ who conducted an intraperitoneal injection to rats 7 days after bilateral suprarenalectomy, a very high sensitiveness as one hundred times was detected for the operated on in comparison with the controls. In another publication of $\mathrm{J}$ aff $\mathrm{e}^{217}$ the results on rats long surviving double decapsulation were discussed. No gross accessories were found in the rats, which died after injecting: a small dose of typhoid vaccine as about one tenth of the M. L. D. for normal ones, while the animals possessing gross accessories were not killed by a somewhat larger amount of the vaccine. No sufficient amounts for comparing resistance between them and the normal ones were obtained in his experiments however.

Gottesman and Gottesman ${ }^{22}$ added from the laboratory of Marine that suprarenalectomized rats have a refractory period of approximately four days before any marked drop in resistance is manifest. On repeating the experiments they noted further that different lots even of so called standard typhoid vaccine, showed wide variation in toxicity.

While all the previous experiments with typhoid vaccine were thus carried out on rats the following data originated from the experiments on rabbits and in fact those which survived double suprarenal ablation by 48 to 110 days, mean 78 days, the first ablation 62 to 166

19) J a f fe and Mrarine, Proc. of Soc. Exp. Biol. and Med., 1923-24, 21, 64; J. of Infect. Dis., 1924, 35, 384 .

20) Shiozawa, Jikken Igaku Zasshi, 1926, 10, 170.

21) J a f e, Am. J. of Path., 1926, 2, 421.

22) Gottesman and Gottes man, Prof. of Soc. Exp. Biol. and Med., 1926(-27),

24, 45; J. of Exp. Med., 1928, 47, 503. 
days, mean 91 days. Therefore this investigation corresponds to a portion of the recent report of $\mathrm{J}$ affe. ${ }^{21)}$

Methods and symptoms: Typhoid vaccine of the Government Institute for Infectious Diseases, Tokyo Imperial University, used in the present investigations contains $0.3 \mathrm{mgrm}$. of typhoid bacilli in 1 c.c. of 0.5 per cent carbolic acid saline solution. This was injected intraperitoneally in doses varying from 5 c.c. to 130 c.c. When a large amount of fluid was given, some difficulties occurred such as leak of fluid from an injection hole against which some precaution was needed or oedema formation in subcutaneous tissue. With this typhoid vaccine the influence of the vehicle itself cannot be avoided from occuring; the symptoms due to the vehicle were similar to those taking place in applying the vaccine fluid, as the following descriptions show.

With a small dose of the vaccine as smaller than 20 c.c. per kilo for doubly decapsulated rabbits or 50 c.c. for normal ones, the animals soon become restless and walked with convulsive-like movements, often lay down on their side, but some minutes later these symptoms almost disappeared, only respiration and pulse were still somewhat quick for a while. With a large amount of the vaccine, the animal fell on its side without reflexes soon after injection, convulsive-like movement of the whole body, the pulse rate very quick, the pupils dilated, corneal reflex disappeared, lacrimation occurred. Then convulsive movements occurred but weak, the heart beat and respiration weaker and weaker, finally the animals died, or otherwise heart beat and respiration became quicker and the animals tried to get up first in vain but finally were capable of taking a normal position but staggered, micturition and defaecation occurred. For a long time the animals rested with the fur ruffled. Genreally animals returned to normal 2 days after injection, but some died under collapse.

The poisoning symptoms with $0.5 \%$ carbolic acid saline solution will be illustrated by the next example which is quite indistinguishable from the typhoid vaccine used.

A white male rabbit, 2.03 kilos. (12. V. 1929 , room temperature $21^{\circ} \mathrm{C}$.) 203 c.c. $0.5 \%$ carbolic acid saline solution ( 100 c.c. per kilo). 1:45 p.m. Injection, soon fell over on its side unconsciously, convulsive movements of the whole body, pupils dilated, respiration and heart rate quick; $2: 23$ Respiration and heart rate very quick, corneal reflex inactive, lacrimation; 7:0 Spastic movements of the whole body became weaker and weaker, respiration slow and weak, heart beat feeble, finally respiration stopped.

Further no distinguishable findings were obtainable in necropsy between the cadavers of normal as well as suprarenalectomized rabbits, died of the typhoid vaccine and of the normal rabbits killed by the carbolic acid saline solution.

Only there was some difference in the toxicity between both the kind s of fluids when one and the same amounts are compared, but we are not certain whether or not it is justifiable to assume the difference as only due to the ty phoid vaccine itself. It is wholly ont of question that the intoxication observed in the present experiments was chiefly, at least, due to the vehicle itself. At present we are dealing with the present results simply as the consequence of the typhoid vaccine fluid with the compositions above given. A note of Steintzer (in Kraus and Levaditi, Handbuch der Technik und Methodik der Immunitätsforschung, I., Jena 1908, 199, that the endotoxine of typhoid bacillus produces neither charac- 
teristic pathological changes nor characteristic clinical symptoms, is worthy of cited here.

\section{Results :}

Dose: 130,120 and 110 c.e. typhoid vaceine per kilo body weight. For rat 100 c.c. typhoid vaccine (prepared by heating 24 hours' cultivation) per kilo were proved sometimes fatal, sometimes not, in the hands of Shiozawa. Each rabbit receiving the above amounts died with the symptoms above described at the end of 8 hours: 10 minutes, $0: 45$ and $6: 28$ respectively. Another rabbit was also killed by 110 c.c. vaccine within 20 minutes.

Dose: 100 e.e. Of 5 control rabbits 4 died about $1: 30$ to $7: 30$ after injection, and one rabbit showed violent poisoning symptoms, but became wakened $2: 35$ after injection and afterward it looked apparently normal, nevertheless it died 19:35 hours after injection.

Dose: 90 c.c. Of 5 control rabbits, one survived and 4 died. 3 rabbits became unconscious and died, but one restored its consciousness once and held the normal posture 2 hours after injection, but suffered from diarrhoea, and about 20 hours later convulsions occurred and it died. The rest suffered from poisoning, but recovered consciousness 3 hours later and then ormal posture was retained at the end of 4 hours: 15 minutes after injection.

Dose: 80 c.c. Of 4 controls 2 survived but 2 died. One rabbit regained consciousness $1: 36$ after injection, 10 minutes later the animal kept the normal posture only with fur ruffled and diarrhoea, the next day it was wholly normal. The second rabbit regained consciousness about two hours after injection, 30 minutes later the normal posture with quick respiration, two days later wholly normal. The third and fourth recovered consciousness $1: 39$ or $2: 7$ respectively after injection and then the normal posture, but fell again and finally death ensued.

Dose: 70 c.e. This dose was applied to a rabbit with both glands removed. It was 56 days after the last ablation, it lay down in an insensible state soon after injection, but regained consciousness $1: 36$ later, then the normal posture only with quick respiration and pulse. Later however he died.

Dose : 60 c.c. All 5 suprarenalectomized rabbits died. Two did not show any recovery of consciousness until they died at the end of $0: 33$ or $4: 10$ after injection respectively. The other 3 rabbits restored once nearly the posture with the fur ruffled for a long time, but the next day they lay down, respiration first quick, then weak and finally convulsions occurred followed by death $(16: 17-24: 50)$. Of 5 control animals 4 survived and one died. They all suffered from 
Table $\mathrm{X}$.

Typhoid vaccine to the rabbits, long surviving the double

suprarenalectomy.

\begin{tabular}{|c|c|c|c|c|c|c|c|c|c|c|c|c|c|}
\hline \multirow[b]{2}{*}{ 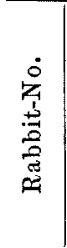 } & \multirow[b]{2}{*}{ 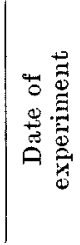 } & \multirow{2}{*}{ 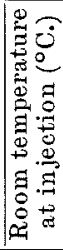 } & \multicolumn{3}{|c|}{$\begin{array}{c}\text { Body weight } \\
\text { (kilos) at }\end{array}$} & \multicolumn{3}{|c|}{$\begin{array}{c}\text { Days } \\
\text { between }\end{array}$} & \multirow{2}{*}{ 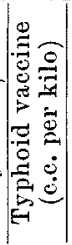 } & \multirow[b]{2}{*}{ 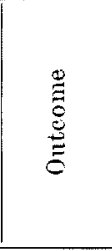 } & \multirow{2}{*}{ 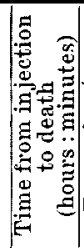 } & \multicolumn{2}{|r|}{ Autopsy findings } \\
\hline & & & 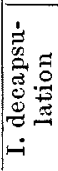 & 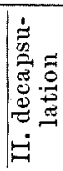 & 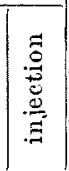 & . & 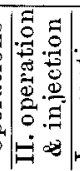 & 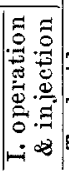 & & & & 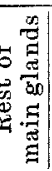 & $\begin{array}{c}\text { Accessory cortical } \\
\text { masses }\end{array}$ \\
\hline & $8\left(\begin{array}{l}(1929) \\
21 . V\end{array}\right.$ & 20 & 1.93 & $8 \mid 1.89$ & 9.24 & 15 & 107 & $\mid 122$ & 5 & survived & & & \\
\hline 42 & 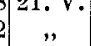 & $\begin{array}{c}20 \\
n\end{array}$ & $\begin{array}{l}1.95 \\
1.79\end{array}$ & 1.86 & 2.24 & $\begin{array}{l}15 \\
15\end{array}$ & $\begin{array}{l}10 \% \\
109\end{array}$ & 117 & 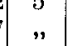 & starvived & & & $\begin{array}{l}1 \mathrm{~mm} . \text { on inferior } \\
\text { a. } 1.5 \times 1.5 \times 1.5 \mathrm{~mm} \text {. }\end{array}$ \\
\hline 086 & 6 6.V. & 15 & 1.85 & 1.80 & 1.95 & 14 & 98 & 107 & $"$ & died & $2: 10$ & 0 & $7\left\{\begin{array}{l}\text { on R epididymis. } 1 \mathrm{~mm} . \\
2.5 \times 1.5 \times 1.5 \mathrm{~mm} . \\
\times 1.5 \times 1.5 \\
\times 1.5 \mathrm{~mm} \text {. and } 1.5 \mathrm{~mm} \text {. on } \\
\mathrm{L} \text { epididymis. }\end{array}\right.$ \\
\hline 080 & $\begin{array}{ll}0.4 . \\
0\end{array}$ & 10 & 1.08 & 1.65 & 1.52 & 14 & 48 & 62 & 10 & sturnted & & & $2.5 \times 1.5 \times 1.5 \mathrm{~mm}$. on front \\
\hline 11 & $22 . \mathrm{V}$. & 20 & 2.37 & 2.34 & 2.43 & 9 & 99 & 108 & , & died & $12: 53$ & 0 & $\mathbf{R}$ epidid \\
\hline 23 & $"$ & $"$ & 2.32 & 2.29 & 2.29 & 9 & 99 & 108 & , & survived & & & i $\mathrm{L}$ epididymis. \\
\hline 51 & $17 . \mathrm{V}$. & 18 & 1.95 & 1.85 & 1.86 & 15 & 93 & 108 & 20 & died & $1: 30$ & 0 & $4\left\{\begin{array}{l}2 \mathrm{~mm} . \text { above } \mathrm{I} \text { kidney. } \\
3 \mathrm{~mm}, 2 \text { mm. and } 1 \mathrm{~mm} . \\
\text { on } \mathrm{R} \text { epididymis. }\end{array}\right.$ \\
\hline & ", & $n$ & 1.94 & 1.79 & 1.93 & 15 & 93 & 108 & 3 & ", & $2: 28$ & 0 & $3\left\{\begin{array}{l}1.5 \mathrm{~mm} \text {. on inferior cava. } \\
1 \mathrm{~mm} \text {. on lateral front } \\
\text { of } \mathrm{L} \text { idney. } 3 \times 2.5 \times 2.5 \\
\mathrm{~mm} \text {. on } \mathrm{L} \text { cpididymis. }\end{array}\right.$ \\
\hline 089 & " & $"$ & 1.66 & 1.64 & 1.95 & 8 & 60 & 68 & 8) $"$ & " & $3: 13$ & 0 & $6\left\{\begin{array}{l}1.5 \mathrm{~mm} . \text { below L kidnes. } \\
2-1 \mathrm{~mm} . \text { and } 2 \text { mm. on } \\
\mathrm{R} \text { epididymis. } 6 \times 3.5 \times 3 \\
\mathrm{~mm} \text {. and } 1 \mathrm{~mm} \text {. on L epi- } \\
\text { didymis. }\end{array}\right.$ \\
\hline 83 & ", & $"$ & 1.90 & \begin{tabular}{l|l}
0 & 1.92 \\
\end{tabular} & 1.92 & 8 & 78 & 86 & $"$ & $"$ & $21: 3$ & 0 & $4\left\{\begin{array}{l}1.5 \times 1 \times 1 \mathrm{~mm} . \text { on fnferior } \\
\text { cara. } 4 \times 3 \times 1.5 \mathrm{~mm} ., \\
\text { mm. and } 1 \mathrm{~mm} . \text { on L epi- } \\
\text { didymis. }\end{array}\right.$ \\
\hline & $"$ & $"$ & 1.98 & 2.07 & 2.00 & 8 & 76 & 84 & 30 & $"$ & $20: 48$ & 0 & $\begin{array}{l}2.5 \mathrm{~mm} \text {, and } 1 \mathrm{~mm} . \\
\text { ididymis. } 2.5 \times 2 \\
\text { a. on } R \text { epididy- }\end{array}$ \\
\hline 40 & $22 . \mathrm{V}$. & 20 & 1.82 & 1.84 & 1.90 & 15 & 110 & 125 & 40 & survived & & & \\
\hline 36 & " & ", & 1.81 & 1.80 & 1.93 & 56 & 110 & 166 & 50 & died & $17: 57$ & 0 & $\begin{array}{l}\text { m. on } R \text { epididymis. } \\
\times 2 \mathrm{~mm} \text {. on L epididy- }\end{array}$ \\
\hline 099 & 9. V. & 15 & 1.53 & 1.57 & 1.63 & 14 & 48 & 62 & , & survived & & & \\
\hline 11 & $16 . \mathrm{V}$ & 16 & 1.66 & 1.61 & 1.65 & 8 & 70 & 78 & , & died & $5: 57$ & 0 & $2\left\{\begin{array}{l}\text { jidnes. } 1 \mathrm{~mm} . \text { below } \mathrm{R} \\
\text { kidnepi- } \\
\text { didymis. }\end{array}\right.$ \\
\hline 79 & " & $"$ & 1.80 & 1.78 & 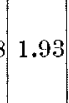 & 8 & 71 & 79 & $"$ & ," & $5: 41$ & 0 & $3\left\{\begin{array}{l}2.5 \times 2.5 \times 2 \mathrm{~mm}, \text { above } \mathrm{L} \\
\text { kidnev. } 2 \times 2 \times 2 \mathrm{~mm} \text {. and } \\
3 \times 2 \times 2 \times \mathrm{mm} \text {. on } \mathrm{R} \text { epididy } \\
\text { mis. }\end{array}\right.$ \\
\hline B 35 & $"$ & $"$ & 1.77 & 1.75 & 2.04 & 8 & 72 & 80 & ) & $"$ & $10: 47$ & 0 & 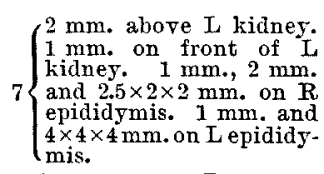 \\
\hline B 1 & $114 . \mathrm{V}$. & $"$ & 1.80 & 0.81 & 2.09 & 8 & 72 & 80 & " & $"$ & $6: 12$ & 0 & $3\left\{\begin{array}{l}2 \times 1 \times 1 \mathrm{~mm} \text {. on } R \text { epididy- } \\
\text { mis. I mm. and } 3 \times 2 \times 2 \\
\mathrm{~mm} \text { on } \mathrm{L} \text { epididymis. }\end{array}\right.$ \\
\hline В 85 & $515 . \mathrm{V}$. & 19 & 1.80 & 1.70 & 1.87 & 8 & 58 & 66 & 60 & " & $20: 45$ & 0 & $4\left\{\begin{array}{l}2 \text { mm. median side of } R \\
\text { lidney. } 2-1 \text { mm. on } R \\
\text { epididymis. } 2.5 \text { mm. on } \\
\text { L epididymis. }\end{array}\right.$ \\
\hline
\end{tabular}




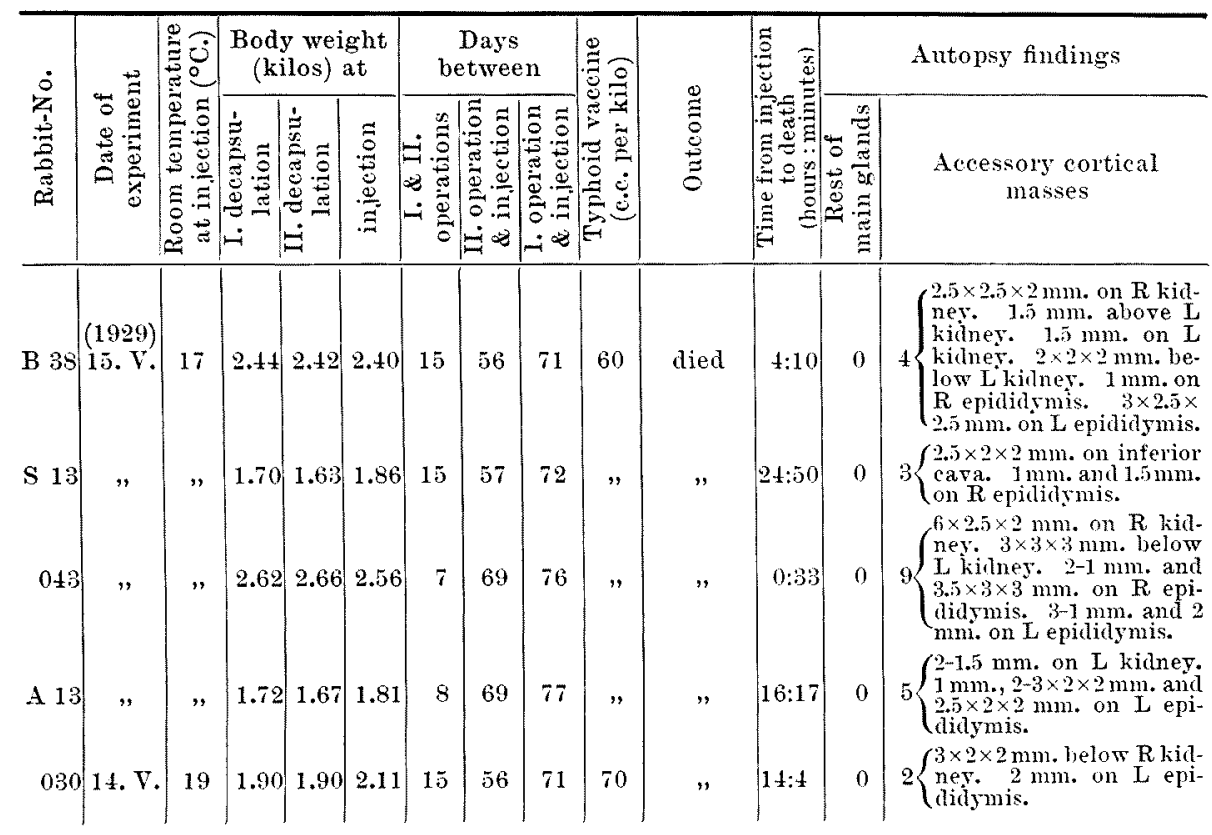

serious poisoning but once regained consciousness; only one rabbit fell down again and died $17: 15$ after injection.

Dose : 50 c.c. 5 suprarenalectomized rabits received this dose intraperitoneally, and 4 died. After recovering the senses, they fell down again and became weaker and weaker, so that they died at last $5: 14$ to $10: 47$ after injection. Only one rabbit survived. Soon after injection the animal lay down on its side unconscious with dilated pupils and violent spastic movements of the whole body for about ten minutes. But it became again conscious and staggered. Diarrhoea. The next day it looked nearly normal but of poor appetite. On the third day wholly normal.

One normal rabbit received this dose, 5 minutes later paresis of hind legs, quick breathing and pulse, spastic movements of the body and pale ear; then restlessness, 45 minutes later the normal condition.

Dose: 10 c.e. This was given to a rabbit 110 days after double suprarenalectomy, which fell over on its side unconscious and died $16: 57$ after injection, though once the normal posture was resumed.

Dose: 30 c.c. A rabbit, which was poisoned 110 days after double decapsulation, fell down once but was able to get rid of further poisoning. A control showed only slight symptoms as quick breathing and pulse. 
TABLE XI.

Typhoid vaceine to normal rabbits.

\begin{tabular}{|c|c|c|c|c|c|c|c|c|c|c|c|c|c|}
\hline 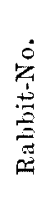 & 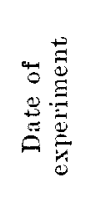 & 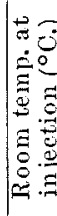 & 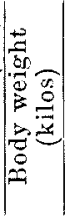 & 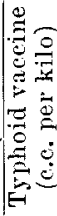 & $\begin{array}{l}\stackrel{0}{\Xi} \\
\stackrel{8}{8} \\
\stackrel{\Xi}{\Xi}\end{array}$ & 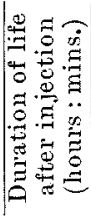 & 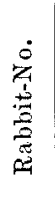 & 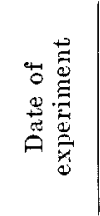 & 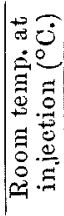 & 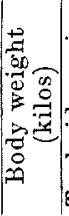 & 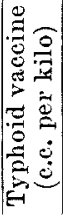 & 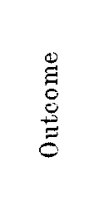 & 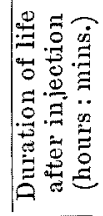 \\
\hline 1 & $\begin{array}{l}(1929) \\
26 . \mathrm{II}\end{array}$ & 15 & & ) 10 & survived & & 5 & $\begin{array}{l}(1929) \\
13 . V .\end{array}$ & 15 & & 90 & died & $1: 25$ \\
\hline $\begin{array}{l}1 \\
2\end{array}$ & 2b. 11. & 15 & $\begin{array}{l}1.80 \\
1.75\end{array}$ & 10 & $\left|\begin{array}{c}\text { survived } \\
,\end{array}\right|$ & & $\begin{array}{l}0 \\
1\end{array}$ & 7. V. & 15 & \begin{tabular}{|l|}
1.64 \\
1.73
\end{tabular} & $\begin{array}{r}90 \\
100\end{array}$ & , & $1: 3$ \\
\hline 1 & & $"$ & 1.73 & 30 & ", & & 2 & $8 . \mathrm{V}$ & 18 & 1.84 & $=$ & $"$ & $6: 5$ \\
\hline 1 & S.IV. & & 1.60 & 50 & ", & & 3 & ", & $"$ & 1.69 & $"$ & 1 & $7: 30$ \\
\hline 1 & $11 . \mathrm{V}$ & 20 & 1.67 & 60 & ", & & 4 & & $"$ & 1.88 & $"$ & $"$ & $4: 20$ \\
\hline 2 & 16. V. & 16 & 1.67 & , & , & & 5 & 13. V. & 15 & 1.73 & 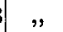 & $"$ & $19: 35$ \\
\hline 3 & $"$ & & 1.71 & $"$ & $"$ & & 1 & 7. V. & " & 1.83 & 110 & $"$ & $0: 20$ \\
\hline 4 & 17. V. & 18 & 2.05 & $"$ & & & 2 & 3. V. & 13 & 1.80 & & $"$ & $6: 28$ \\
\hline$\pi$ & & & 1.79 & 1 & died & $17: 15$ & 1 & , & ", & 1.68 & 120 & 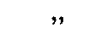 & $0: 4$ \\
\hline 1 & 11. V. & 20 & 1.79 & 80 & survived & & 1 & " & $"$ & 1.6 & 130 & $"$ & $8: 10$ \\
\hline 2 & 21. V. & $"$ & $\mid 1.79$ & " & ( & & \multirow{2}{*}{\multicolumn{7}{|c|}{$0.5 \%$ carbolic acid saline solution. }} \\
\hline 3 & " & $"$ & $\mid 2.04$ & $"$ & died & $3: 20$ & 10 & & & & & & \\
\hline 1 & 9."v. & 18 & 1.73 & 90 & ", & $1: 40$ & 2 & $r$ &, & 1.68 & $"$ & & \\
\hline 2 & $13 . V$. & 15 & 1.92 & " & $"$ & $2: 10$ & 3 & ", & $"$ & 1.70 & " & died & $0: 2$ \\
\hline 3 & & ," & 1.77 & ," & ur & & 4 & & ", & 1.7 & " & , & $1: 3$ \\
\hline 4 & ", & $"$ & 1.88 & 3 & died & $22: 37$ & 5 & 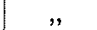 & $"$ & 2.03 & ", & ", & $5: 15$ \\
\hline
\end{tabular}

TABLE XII.

Typhoid vaceine summany table.

\begin{tabular}{c|c|c|c|c}
\hline \multirow{2}{*}{ Dose per kilo } & \multicolumn{2}{|c|}{$\begin{array}{c}\text { Doubly suprarenalectomized } \\
\text { rabbits }\end{array}$} & \multicolumn{2}{|c}{ Normal rabbits } \\
\cline { 2 - 4 } (c.c.) & Survived & Died & Survived & Died \\
\hline 5 & 2 & 1 & & \\
10 & 2 & 1 & 2 & \\
20 & 1 & 5 & 1 & \\
30 & 1 & 1 & 1 & \\
40 & & 4 & 4 & 1 \\
50 & & 1 & 2 & 2 \\
60 & & & 1 & 4 \\
70 & & & & 5 \\
80 & & & & 1 \\
90 & & & & \\
100 & & & & \\
110 & & & & \\
120 & & & &
\end{tabular}

Dose : 20 c.c. All 5 decapsulated animals died on getting 20 c.c. typhoid vaccine 1 to 21 hours later. All the rabbits fell down soon and were attacked by convulsions, but showed a tendency to recover. 
3 rabbits however became weak again and died within a short time after injection. The other two seemed nearly recovered but the next day they died suddenly.

Dose : 10 e.c. 3 suprarenalectomized rabbits were poisoned with 10 c.c. vaccine fluid. One became restless on injection, respiration and pulse quick, pupils dilated, it walked with spastic movements of the body, then respiration became deep, yet quick. The fur ruffled. The next day only the appetite was not yet normal. The second showed parese of the hind legs, spastic movements of the body lying down on its side, but these disappeared readily. In the third paresis of both extremities occurred 36 minutes later, quick breathing, and then coma which was succeeded by convulsive seizures and death.

Dose : 5 c.e. Of 3 suprarenoprived rabbits 2 survived with slight symptoms, while one became unconscious $2: 2$ after injection and some minutes later died.

It was thus determined that the maximum non-lethal dose of the typhoid vaccine containing $0.5 \%$ carbolic acid was 50 c.c. for normal rabbits, less than 5 c.c. for doubly suprarenalectomized ones and the minimum lethal dose as 100 c.c. for the normal and 60 c.c. for the doubly decapsulated.

As pointed out above, however, the toxicity of the vaccine shown thus on rabbits is at least partly or chiefly due to the vehicle itself, judging from the symptoms elicited, and in fact 100 c.c. $5 \%$ carbolic acid saline fluid killed 3 rabbits when applied to 5 , while 100 c.c. vaccine fluid killed all 5 rabbits and 90 c.c. 3 out of 5 . Two rabbits lay down unconscious with convulsive-like movements of the body for about two and a half hours, but regained consciousness and normal posture, only the respiration and pulse were observed to be accelerated, the hind legs were paretic and the fur ruffled. The next day they were wholly normal. The other 3 fell down unconscious immediately after injection and died without showing any recovery at the end of 25 minutes to 5 hours after injection.

The greatest part of the toxicity of the typhoid vaccine solution employed must be therefore attributed to that of the vehicle itself.

\section{Résumé :}

The rabbits surviving 48 to 110 days, mean 78 days, double suprarenalectomy showed a clearly increased susceptibility to the typhoid vaccine intraperitoneally injected compared with the normal ones, the maximum non-lethal dose and the minimum lethal dose being estimated as about one tenth and one half of the normal. The vaccine employed contains 0.5 per cent carbolic acid, and the toxicity of the vaccine fluid as 
observed in the present investigations is found largely due to the vehicle.

What difference in the resistance to typhoid vaccine there exists between normal rats and those long surviving double suprarenalectomy and possessing gross accessories cannot be known from the data of $J$ a f $\mathrm{e}^{21)}$ as above discussed; only it seems strange to us who have experience only on rabbits that some rats deprived of both glands were very sensitive and they all (No description about accessories of $\mathrm{No}_{0}$. 155) were found not posessing any macroscopical accessories, while those which were not so sensitive were found some days (about 70 to 90 days) later as involving some large ones as $6 \times 1 \mathrm{~mm}$., etc.

\section{SUMMaRY.}

Resistance of rabbits, long surviving double suprarenalectomy, to nicotine, histamine, ephedrine and typhoid vaccine (in 0.5 per cent carbolic acid saline solution) was compared with that of normal rabbits. Adult, male animals of about the same weight were experimented on; they were fed and treated otherwise in quite the same manner, and poisoning with one and the same dosage of a chemical was run simultaneously on both kinds of rabbits, normal and decapsulated. Nicotine, histamine and ephedrine were dissolved in physiological saline solution of a certain quantity for each, regardless of amount of the chemical,

\section{TaBLE XIII.}

IIaximum non-lethat dose and minimum lethal dose of acetonitrit, nicotine, histamine, ephedrine and typhoid vaceine (in $0.5 \%$ carbolic acid saline fhid) to normal as well as bilaterally suprarcnalectomized rabbits.

\begin{tabular}{|c|c|c|c|c|c|}
\hline & $\begin{array}{l}\text { Acetonitril } \\
\qquad(\mathrm{c.c} .)\end{array}$ & $\begin{array}{l}\text { Nicotine } \\
\text { (mgrm.) }\end{array}$ & $\begin{array}{l}\text { Histamine } \\
\text { (mgrm.) }\end{array}$ & $\begin{array}{l}\text { Ephedrine } \\
\text { (mgrin.) }\end{array}$ & $\begin{array}{l}\text { Typhoid vac- } \\
\text { cine (in } 0.5 \% \\
\text { carbolic acid } \\
\text { saline solu- } \\
\text { tion) (c.c.) }\end{array}$ \\
\hline & $\begin{array}{l}\text { Normal labbits: } \\
\text { Decapsulated lab- } \\
\text { bits [2 weeks after } \\
\text { I. decapsulation, } 1 \\
\text { week after II.] : De- } \\
\text { capsulated rabbits } \\
\text { [3 weeks after I., } 1 \\
\text { week after II.] De- } \\
\text { capsulated rabbits } \\
\text { [222 (98-372) days } \\
\text { after I., } 107(87-252) \\
\text { days after II.] }\end{array}$ & $\begin{array}{l}\text { Normal rab- } \\
\text { bits : Decap- } \\
\text { sulated rab- } \\
\text { bits [280 ( } 82 \\
-556) \text { days } \\
\text { after I., } 220 \\
\text { (68-478)dass } \\
\text { after II.] }\end{array}$ & $\begin{array}{l}\text { Normal rab- } \\
\text { bits : Decap- } \\
\text { snlated rab- } \\
\text { bits }[212(135 \\
-310) \text { days } \\
\text { after I., } 102 \\
(80-232) \text { days } \\
\text { after II.] }\end{array}$ & $\begin{array}{l}\text { Normal rab- } \\
\text { bits : Decap- } \\
\text { sulated rab- } \\
\text { bits } 190(78 \\
-301) \text { days } \\
\text { after I., } 87 \\
(64-280) \text { days } \\
\text { after II.] }\end{array}$ & $\begin{array}{l}\text { Normal rab- } \\
\text { bits : Decap- } \\
\text { sulated rab- } \\
\text { bits [91 ( } 62 \\
-166) \text { days } \\
\text { afted I., } 78 \\
(48-110) \text { days } \\
\text { after II.] }\end{array}$ \\
\hline $\begin{array}{l}\text { Maximum } \\
\text { non-lethal } \\
\text { dose }\end{array}$ & $\begin{array}{r}0.25^{*}: 0.05 \\
: 0.1: 0.15\end{array}$ & $7^{*}: 8$ & $7^{*}: 0$ & $0.06^{*}: 0.08$ & $<5^{*}: 50(?)$ \\
\hline $\begin{array}{l}\text { Minimum } \\
\text { lethal dose }\end{array}$ & $\begin{aligned} 0.55 * & : 0.4 \\
: 0.5 & : 0.55\end{aligned}$ & $11^{*}: 12$ & $10^{*}: 12$ & $0.1^{*}: 0.12$ & $60 *: 100$ \\
\hline
\end{tabular}

* Indicates the doses for normal rabbits. 
and introduced into the ear vein always with exactly the same velocity. Typhoid vaccine was intraperitoneally injected; the toxicity of this matter is really largely due to the vehicle.

The poisoning symptoms elicited by application of various dosages were closely observed, and the maximum non-lethal dose, that is the greatest dose which is poisonous to animals but does not kill them, and the minimum lethal dose were determined. The results are again summarized in Table XIII, together with the data on acetonitril. ${ }^{1)}$

Resistance to such chemicals was indefinitely smaller in doubly suprarenoprived rabbits than in the normal controls, but the difference was never large in those rabbits long surviving double decapsulation, and the magnitude of diminution in resistance apparently depends at least largely upon the length of time allowed to elapse from the first and the second decapsulation till the injection, and the chemicals, under discussion, themselves have no significant bearing upon them, as far as our experiments are concerned. The present experiments were mainly undertaken about two months after the last decapsulation. We are fully aware that we could get more definite views in respect to this question provided the first and second decapsulation and injection were carried out invariably with definite spells between them. In fact the periods between were taken at random.

That the regaining of resistance to toxines of the animals deprived of both suprarenals with lapse of time after decapsulation has some definite relationship to the hypertrophy of the accessory cortical tissues has been properly alluded to by several experimentalists. In this respect it is worth while to review a work of $\mathrm{K}$ o $\mathrm{im} \mathrm{a}^{23}$ ) on the compensatory hypertrophy of the fellow gland after a single decapsulation and of the accessories after donble capsulation with the present data; some quantitative data are given there.

There are some substances which are alleged to act incomparably excessively toxic to animals deprived of the suprarenals, as acetonitril (100 times) by Crivellari, ${ }^{t)}$ in contrast to nicotine, histamine, etc., typhoid vaccine (100 times by Shiozawa, ${ }^{20)}$ who failed to adhere to Lewis $\mathrm{s}^{2+)}$ in finding a considerably greater increase of susceptibility of rats to morphine through double decapsulation (400-500 times). It is a further question whether or not one can find various degrees of diminution in resistance of rabbits by applying various chemicals if they are administered only a few days after loss of both suprarenals.

Finally the present data may be briefly recapitulated for the sake of convenience by saying that the sensitiveness of rabbits to nicotine, histamine, ephedrine, and typhoid vaccine (in 0.5 per cent carbolic acid saline solution) was not wholly identical but only a little inferior to that of normal, when tested about two, three montlis or somewhat later after double suprarenalectomy.

23) K o ji m a, Tohoku J. of Exp. Med., 1929, 13, $20 \%$

24) Lewis, Am. J. of Physiol., 1923, 64, 506. 